\title{
Integration of Palliative Care in Chronic Critical Illness Management
}

\author{
Judith E Nelson MD JD and Aluko A Hope MD MSCE
}

\author{
Introduction \\ Symptom Assessment and Management \\ Communication About Care Goals \\ Family Support and Transition Planning \\ Models for Integrating Palliative Care and \\ Restorative Critical Care for the Chronically Critically Ill \\ Ethical Issues \\ Summary
}

\begin{abstract}
Palliative care is an essential component of comprehensive care for all patients with chronic critical illness, including those receiving restorative or life-sustaining therapies. Core elements include alleviation of symptom distress, communication about care goals, alignment of treatment with the patient's values and preferences, transitional planning, and family support. Here we address strategies for assessment and management of symptoms, including pain, dyspnea, and depression, and for assisting patients to communicate while endotracheally intubated. We also discuss approaches to optimize communication among clinicians, patients, and families about care goals. Challenges for supporting families and planning for transitions between care settings are identified, while the value of interdisciplinary input is emphasized. We review "consultative" and "integrative" models for integrating palliative care and restorative critical care. Finally, we highlight key ethical issues that arise in the care of chronically critically ill patients and their families. Key words: mechanical ventilation; palliative care; communication; intensive care. [Respir Care 2012;57(6):1004-1012. (C) 2012 Daedalus Enterprises]
\end{abstract}

\section{Introduction}

Palliative care is both a medical specialty and an approach to patient care that focuses on the following core elements: alleviation of symptom distress; communication

Dr Nelson is affiliated with the Division of Pulmonary, Critical Care, and Sleep Medicine, Department of Medicine, Mount Sinai School of Medicine, New York, New York. Dr Hope is affiliated with the Division of Critical Care Medicine, Department of Medicine, Albert Einstein College of Medicine of Yeshiva University, Bronx, New York.

Dr Nelson presented a version of this paper at the 49th RESPIRATORY CARE Journal Conference, "The Chronically Critically Ill Patient," held September 9-10, 2011, in St Petersburg, Florida.

Dr Nelson was partly supported by Academic Career Leadership Award K07-AG034234 from the National Institute on Aging. The authors have disclosed no conflicts of interest. about care goals; alignment of treatment with the patient's values and preferences; transitional planning; and support for both patient and family throughout the illness trajectory. Increasingly, this type of care is seen as an essential component of comprehensive care for all patients with critical illness, including those receiving restorative or lifesustaining therapies. ${ }^{1-3}$ As critical illness enters the chronic phase, close attention to palliative care principles is a paramount responsibility for all clinicians on the treatment team. Accumulating evidence suggests that early integra-

\footnotetext{
Correspondence: Judith E Nelson MD JD, Mount Sinai School of Medicine, 1 Gustave Levy Place, Box 1232, New York NY 10029. E-mail: judith.nelson@mssm.edu.
}

DOI: $10.4187 /$ respcare. 01624 
tion of palliative care can enhance the effectiveness of disease-directed treatment for patients with serious and complex illness, ${ }^{4,5}$ while improving the quality of their lives, supporting their families, and promoting efficient use of expensive resources. ${ }^{4,6,7}$ In this article we address needs, challenges, and strategies for palliative care during chronic critical illness (CCI).

\section{Symptom Assessment and Management}

Symptom distress is such a common experience for chronically critically ill patients, it has been included as a defining feature of the syndrome of CCI. ${ }^{8}$ In a prospective study of patients treated in a respiratory care unit of an acute care hospital after elective tracheotomy for failure to wean from mechanical ventilation in the ICU, three fourths of those who could self-report symptoms in real time experienced $\geq 10$ of 16 symptoms included in the assessment tool (modified from the Condensed Form of the Memorial Symptom Assessment Scale). ${ }^{9}$ Over $40 \%$ of the patients reported pain at the highest levels on the scale, and more than $60 \%$ reported psychological symptoms (sadness, worry, and nervousness) "frequently" or "almost constantly." Other physical symptoms including unsatisfied thirst and dyspnea (on full ventilator support as well as during weaning) also caused substantial distress for many patients. Approximately $90 \%$ of patients reported maximal distress due to difficulty communicating as a result of endotracheal intubation.

Jubran et al subsequently conducted a prospective study of almost 500 patients transferred to a long-term acute care facility for weaning from prolonged mechanical ventilation. ${ }^{10}$ Of 336 patients who could be evaluated, over $40 \%$ met criteria for a depressive disorder in the Diagnostic and Statistical Manual of Mental Disorders IV.11 Duration of mechanical ventilation was twice as long for depressed patients, and they were 3 times more likely to remain ventilator dependent than those without a depressive disorder. Patients with depression were also more than twice as likely to die in the facility as those without depression, and this increased rate of mortality remained substantial after controlling for age, comorbid illness, and other independent predictors of death. These data add to a growing body of evidence associating physical and emotional symptom distress with unfavorable outcomes, while associating regular assessment and effective management of symptoms with shorter duration of mechanical ventilation and other favorable results. ${ }^{12-14}$

Given the prevalence, intensity, and broader implications of distressing symptoms among chronically critically patients, optimal care of these patients must address their comfort needs systematically and effectively. Systematic symptom assessment is an essential first step, but can be challenging when patients are impaired by brain dysfunc- tion and inability to communicate, as is so common during CCI. ${ }^{15}$ Many patients are able to provide self-reports of their symptoms, ${ }^{9}$ which remain the gold standard for symptom assessment. For this purpose, the evaluative tool must be short and simple, like the Condensed Form of the Memorial Symptom Assessment Scale ${ }^{16}$ or Edmonton Symptom Assessment Scale, ${ }^{17}$ measuring a diverse group of symptoms, or an abbreviated instrument focused on a specific symptom such as pain, dyspnea, or depression. ${ }^{18-20}$ Several tools are available to assess symptoms such as pain and dyspnea among patients who cannot self-report (eg, Behavioral Pain Scale, ${ }^{21}$ Critical Care Pain Observation Tool, ${ }^{22}$ Assume Pain Present approach, ${ }^{23}$ and Respiratory Distress Observation Scale ${ }^{24}$ ), although use in chronically critically ill patients has not, to our knowledge, been reported.

To date, no published studies have evaluated interventions to alleviate symptoms in the specific context of CCI. Even in acute critical illness, scant evidence from rigorous research is available to inform symptom management, and distinctive features of CCI may limit generalizability of data from the ICU. However, studies in other seriously ill patient groups, expert recommendations, and clinical experience with the chronically critically ill support several key principles for effective symptom management. First, symptoms in this population are best addressed in the context of a comprehensive assessment because they may be exacerbated by positional, procedural, spiritual, social, and psychological factors that need concomitant attention. Second, most patients have multiple symptoms, and there may be interactions among these symptoms and among their treatments. Third, given the risks associated with polypharmacy in this patient group, " $n$ of 1 " trials of non-pharmacologic approaches, including complementary and alternative interventions, ${ }^{25,26}$ should be explored early in suitable and receptive patients.

For moderate to severe pain during CCI, clinical experience supports the preferential use of opioids as the safest and most effective class of medications. When renal function is impaired, as is common among the chronically critically ill, hydromorphone may be a better choice than morphine, which has active metabolites that accumulate and can cause prolonged sedation ${ }^{27}$ and neuronal excitation. ${ }^{28}$ Fentanyl can be administered by several alternative routes, including bolus intravenous dosing for short-acting analgesia during painful procedures (eg, care of deep pressure ulcers), and transdermal fentanyl for continuous opioid analgesia without intravenous access. Knowledge of equi-analgesic opioid dosing is important; this information is readily incorporated in computer-based ordering systems and/or on pocket cards for clinicians. ${ }^{29}$ For dyspnea, non-pharmacologic approaches such as use of a fan, relaxation, or meditation techniques, or pursed lip breathing may be helpful. ${ }^{30}$ Opioids are also effective in treating 
dyspnea, usually at much lower doses than are used to treat pain. Tolerance to side effects of opioid treatment, such as excessive sedation, tends to develop more quickly than tolerance to the primary treatment effect, but may require specific therapeutic strategies that have been described previously. ${ }^{31,32}$

Multiple techniques and tools at different levels of complexity and sophistication are available to assist endotracheally intubated patients to communicate. ${ }^{33}$ Some chronically critically ill patients tolerate placement of a tracheostomy speaking valve, allowing them to speak intelligibly with staff and family. ${ }^{34}$ To supplement speech (or provide a sole avenue of communication for those who cannot vocalize through a speaking valve), patients may be offered an alphabet board or a communication board, to which either they or a caregiver (with affirmation from the patient through nodding or other signaling) can point. ${ }^{33}$ Other options to enhance communication include touch screens and specialized key pads that can translate minimal physical pressure into synthesized speech, but the cost of such devices may limit their availability. ${ }^{33}$ Although many chronically critically ill patients may be too debilitated or delirious to make use of any of these methods, clinicians should make every effort to facilitate communication, given its importance to patients and their caregivers. When successful, as has been reported in case series, ${ }^{33,34}$ such efforts not only address one of the most important sources of symptom distress during CCI, but may enable patients to provide self-reports of their experience to clinicians, express their emotions and thoughts to loved ones, and participate in discussions of treatment goals and preferences.

Rigorous data are lacking to guide treatment of depression in the specific context of CCI. In our clinical experience, appreciation of both the patient's prognosis (for survival and/or ventilator liberation) and prior psychiatric history can be helpful in choosing the most appropriate treatments (pharmacologic and/or non-pharmacologic). Selective serotonin reuptake inhibitors are well tolerated by these patients, but response latency may be too long to improve mood or energy during initial weeks of weaning efforts. For more rapid onset of action, we have had success with the use of psychostimulants such as methylphenidate at low doses, without untoward effects. ${ }^{35,36} \mathrm{~A}$ consultant with psychopharmacology expertise may be helpful in selecting adjunctive therapies in this patient population. $^{25}$

\section{Communication About Care Goals}

Communication about care goals in the context of CCI is often complicated for several reasons. First, the patient's very survival of the acute phase of critical illness may give the family unfounded hope for a meaningful recovery.
Qualitative research suggests that families often misperceive the placement of tracheotomy as a sign that the patient is progressing toward ventilator liberation and eventual recovery. ${ }^{37}$ Second, since most patients move to one or more different care settings for the chronic phase of their illness, ${ }^{38}$ ICU clinicians may themselves fail to appreciate the high risks of mortality and severe morbidity after ICU discharge, ${ }^{39}$ or may choose to defer communication about these risks. ${ }^{39}$ Third, fragmentation and discontinuity of care tend to increase as critical illness continues over a prolonged period, creating obstacles to coordinated, consistent communication.

Critical care guidelines endorse a shared decisionmaking model in which both the patient and the clinician play an active role, ${ }^{40}$ but there is a wide continuum of preferred roles in decision making among patients and families, and clinicians need to be flexible to facilitate decisions that are most consistent with the patient's values and preferences. ${ }^{41}$ Chronically critically ill patients are usually unable to participate directly in communication and decision-making, ${ }^{15}$ and few have formally designated a surrogate decision-maker or prepared another advance directive. ${ }^{42}$ Thus, discussions and decision-making about goals of care usually involve the patient's family or other surrogates, who may lack sufficient knowledge of the patient's preferences ${ }^{43}$ or who may be burdened by psychological or practical issues ${ }^{44}$ that serve as barriers to patientfocused decision making.

Goals of care are ideally determined through a series of proactive, sensitive, and structured discussions in which the patient and/or surrogates receive information about the nature and prognosis of the illness, and consensus is achieved on therapeutic options that are consistent with the patient's values and preferences. These goals of care may shift in relation to observed effect of restorative treatment, but such shifts are difficult to make abruptly. In our experience, a slower, incremental approach, proceeding with patience over a series of discussions, is ultimately more effective and efficient in achieving consensus. Contributions from multiple members of the interdisciplinary team are helpful in meeting the challenges of this type of communication. The role of the patient's nurse in ICU family meetings has recently been highlighted, ${ }^{45}$ and extends into the chronic phase of critical illness. As reviewed more fully elsewhere, active participation by the nurse in discussions about goals of care is appropriate and important for many reasons. ${ }^{45,46}$ Involvement of other disciplines, such as social work, chaplaincy, and respiratory therapy, and engagement of palliative care and/or ethics consultants, can also enhance communication with families of the chronically critically ill. To ensure that input from all members of the interdisciplinary team is integrated and that a consistent approach is taken with the family, the team should always "pre-meet" themselves before a fam- 


\section{Integration of Palliative Care in Chronic Critical Illness Management}

ily meeting and discuss the family meeting after in a debriefing session. In addition, key information exchanged during the family meeting should be documented in the medical record so that all members of the team understand the status of ongoing communications with the family.

Qualitative investigation of ICU family conferences suggests specific skills and approaches that may improve the efficacy of communication by clinicians. Whereas physicians tend to dominate discussions with families, this research indicates the importance of listening ${ }^{47}$ : family satisfaction has been associated with the proportion of time the family speaks in these meetings, relative to the time in which clinicians are speaking to the family. An effective approach to encourage comments and questions from family members is summarized as "Ask, Tell, Ask." 48 The clinician begins the discussion by asking family members to report their understanding of a situation (eg, the patient's condition and prognosis), and by asking permission to continue with the discussion. The clinician then provides a succinct update of the situation in layperson's terms. The family is then asked again to summarize the discussion, comment, and ask questions.

Studies in the ICU and other settings indicate that physicians frequently miss opportunities to acknowledge and address the family's emotions. ${ }^{49,50}$ Families are more satisfied, however, when their emotions are explicitly addressed by clinicians. In addition, strong emotions can overwhelm the ability to absorb and integrate information needed for rational decision-making. ${ }^{51}$ Thus, communication should incorporate expressions of empathy, which help to modulate emotional fluctuation and distraction. ${ }^{52}$ The acronym NURSE has been suggested to summarize statements that communicate empathy explicitly: Name the emotion to make clear that it is recognized; express Understanding in an open and compassionate way; show Respect for the person experiencing the emotion; communicate Support; and Explore the emotional experience of the other person in greater depth (Table 1). ${ }^{53}$

When communication addresses limitation of life support, research suggests that families are more satisfied when clinicians provide assurance that the patient will not be abandoned prior to death and will not suffer, and support the family's decision whether to forgo or continue the therapy. ${ }^{54}$ Expert recommendations have been provided for approaching patients and family members who prefer continuation of life-supporting treatments based on the belief that a miracle will occur, ${ }^{55}$ and those who insist on "everything" despite a clinician's view that the treatments will not have meaningful benefit. ${ }^{56}$ Communication of prognostic information is particularly challenging. Most family decision-makers and other surrogates lack knowledge of the nature and expected outcomes of CCI, but consider this information important. ${ }^{37,39,57}$ In one study, for example, the vast majority of surrogates for chronically
Table 1. Communication About Goals of Care: Essentials of an Effective, Evidence-Based Approach*

\begin{tabular}{|c|c|}
\hline Proactive & $\begin{array}{l}\text { Meet proactively with the family, beginning } \\
\text { early in the critical illness and continuing } \\
\text { periodically. Goals of care may shift in } \\
\text { response to observed effect of treatment, } \\
\text { but incremental discussion is more } \\
\text { effective than abrupt change. }\end{array}$ \\
\hline Interdisciplinary & $\begin{array}{l}\text { Involve multiple members of interdisciplinary } \\
\text { team, including the nurse, using pre- } \\
\text { meeting and post-meeting debrief strategies } \\
\text { to ensure consistent, coordinated } \\
\text { communication by the team. }\end{array}$ \\
\hline Structured & $\begin{array}{l}\text { Key elements for discussion to define } \\
\text { achievable and appropriate goals of care } \\
\text { include the patient's condition, treatments, } \\
\text { and prognosis; the family's understanding } \\
\text { of the patient's goals, values, and } \\
\text { preferences; and the family's own concerns } \\
\text { and needs. }\end{array}$ \\
\hline Family engaged & $\begin{array}{l}\text { Engage family to participate actively using } \\
\text { the "Ask, Tell, Ask" approach and } \\
\text { adjusting the balance of time in which } \\
\text { clinicians speak versus listen to concerns } \\
\text { expressed by family. }\end{array}$ \\
\hline Empathic & $\begin{array}{l}\text { Attend to family emotions, using strategies } \\
\text { including explicit communication of } \\
\text { empathy (NURSE mnemonic summarizes } \\
\text { empathic statements) and assurances of } \\
\text { patient comfort and of non-abandonment of } \\
\text { patient or family. }\end{array}$ \\
\hline Documented & $\begin{array}{l}\text { Summarize discussion in medical record so } \\
\text { that all members of team understand the } \\
\text { status of communication and current goals } \\
\text { of care. }\end{array}$ \\
\hline
\end{tabular}

* The table summarizes key components of the recommended approach, discussed more fully in the text, to communication about goals of care for patients with chronic critical illness.

critically ill patients with recent tracheotomy reported that they received no information about possible functional dependence at discharge or about prognosis for 1-year survival, respectively. ${ }^{57}$ In another study, Cox et al found that families were far more optimistic than their physicians about long-term outcomes for patients on prolonged mechanical ventilation. ${ }^{39}$ Over $90 \%$ of families expected the patient to survive for at least a year (compared to $44 \%$ of the physicians), and more than $70 \%$ of families anticipated no major functional impairment (compared to $6 \%$ of the physicians). ${ }^{39}$ This discordance of expectations suggested that communication between physicians and families could be improved. ${ }^{39}$ Other factors contributing to overestimation of prognosis by families include health optimism, intuition, and overriding faith in God. ${ }^{58,59}$ Exploration of such factors may help the clinician to provide prognostic information and support decision-making in more meaningful and appropriate ways. Again, attention to family emotions is essential in enhancing the capacity of the fam- 


\section{Integration of Palliative Care in Chronic Critical Illness Management}

ily to hear and act upon information communicated by clinicians.

Several tools have recently become available to support effective and efficient communication with families of the critically ill. First, a new prognostic model, "ProVent," uses 4 easily collected variables (age, platelet count, and use of vasopressors and hemodialysis) to estimate 1-year survival of patients requiring prolonged mechanical ventilation. ${ }^{60}$ This simple model, which has been validated in multiple centers, can help inform discussions of the risk of mortality for the chronically critically ill patient, although more research is needed to guide effective incorporation of such information in a broader discussion of appropriate goals of care. Second, a brochure for families about CCI, which was developed and validated with sponsorship from the National Institutes of Health Clinical Center's Department of Bioethics, and from the Patient and Family Support Committee of the Society of Critical Care Medicine, is available. ${ }^{61}$ This brochure uses a question-and-answer format to address issues including: What is CCI? What treatment is available? Do chronically critically ill patients regain the ability to breathe on their own? Can patients with CCI live on their own? What is the experience like for families? What is a tracheotomy? and What are the options? An ongoing randomized controlled, multicenter trial funded by the National Institutes of Health is evaluating the impact on family well-being and other outcomes of this brochure along with protocol-guided family meetings led by palliative care specialists, compared to the brochure with usual care. The value of printed informational materials for educating families of ICU patients has previously been shown in rigorous studies. ${ }^{62,63}$ In addition, a Family Meeting Guide can be given to families to help them prepare for an upcoming discussion. ${ }^{64,65}$ This guide encourages families to gather relevant information and materials, focus on specific topics (examples are provided), and write down questions for clinicians.

A variety of templates for physician documentation of family meetings are available for use or adaptation to meet local needs. ${ }^{66}$ Such templates can enhance efficiency, and, if key topics for discussion are included, can also provide a framework for the meeting. Proper documentation of the family meeting also supports appropriate physician reimbursement. If the patient is critically ill or injured, the critical care codes 99291 and 99292 allow physicians to report time spent in meetings with surrogates under the following circumstances: the patient lacks capacity to participate directly in the discussion and decision-making, and the discussion is necessary for decision-making about medical treatment. ${ }^{67}$ For the purposes of these codes, critical care time would thus include properly documented discussions about use or limitation of cardiopulmonary resuscitation (ie, whether to attempt resuscitation or not attempt resuscitation in the event of an arrest), and dis- cussions in connection with medical decision-making about use or limitation of other treatments such as mechanical ventilation, renal replacement therapy, and artificial nutrition and hydration. In addition, if the patient has capacity to participate, communication with the patient's family or other surrogate decision-maker can still be reported as critical care time under these codes, provided that the patient is present for the discussion and treatment options are discussed. ${ }^{67}$

\section{Family Support and Transition Planning}

As critical illness becomes chronic, the emotional, physical, and practical burdens for families weigh heavily. On average, the length of the acute hospital stay for chronically critically ill patients is 2 months, and hospital survivors spend $75 \%$ of their days during the year after their illness in institutional care or with paid home assistance. ${ }^{38}$ Families' personal and professional lives are often substantially disrupted during this time. ${ }^{68-70}$ A study by Swoboda and Lipsett found that most families of patients with prolonged surgical illness were providing assistance throughout the year after the illness, often leaving their paid employment and depleting their savings. ${ }^{68}$ Others have reported similar findings for families of patients on prolonged mechanical ventilation during medical or surgical illness or after trauma. ${ }^{69}$ Like informal caregivers for other patients with chronic illness, ${ }^{71}$ those caring for the chronically critically ill experience substantial decrements in physical health as well as role overload and burden that accumulate over time. ${ }^{72}$ Depression is highly prevalent among these families, and multiple studies suggest that depression is more severe for those whose loved ones are institutionalized than for those caring for patients at home. ${ }^{73,74}$ Acute and post-traumatic stress symptoms affect families of patients surviving acute critical illness, ${ }^{75-77}$ and in light of evidence suggesting that symptoms of posttraumatic stress disorder increase over time for these families, ${ }^{77,78}$ it is likely that families of the chronically critically ill are also affected. ${ }^{79}$ In follow-up interviews with bereaved family members of patients who died in the ICU, one third met Diagnostic and Statistical Manual of Mental Disorders-IV criteria for at least one psychiatric disorder (major depression, generalized anxiety, panic, or complicated grief). ${ }^{80}$

Interdisciplinary support and transitional planning are important for families of the chronically critically ill, although models for delivering this care need further investigation. Douglas et al evaluated a disease management program for patients with prolonged mechanical ventilation (median duration of mechanical ventilation was $8 \mathrm{~d}$ ) and their families. ${ }^{81,82}$ The 8-week intervention was implemented in a single center by an advanced practice nurse who provided emotional support, care coordination, edu- 
cation, and case management services to the patient and the caregiver before and after hospital discharge. Compared to usual care, this intervention was not associated either with lower rates of readmission for these patients or with lower depression, burden, or physical health among caregivers. The effect of a structured communication and support intervention from a palliative care physician and nurse, with optional participation by the critical care physician, is currently being studied in a randomized controlled trial (NCT 01230099 ClinicalTrials.gov) enrolling patients who have been mechanically ventilated for $\geq 7$ days and are not expected to wean or to die in the near future. Outcomes of this study include psychological wellbeing of the patient's family or other surrogate medical decision-maker. While the results of ongoing and future research are awaited, clinicians are encouraged to engage an interdisciplinary team to address families' emotional, spiritual, and practical needs. Support for family members enables them to function more effectively as caregivers and surrogate decision-makers, thereby benefiting patients and clinicians as well as themselves.

\section{Models for Integrating Palliative Care and Restorative Critical Care for the Chronically Critically III}

For integrating and improving palliative care in the ICU, 3 main models have been described: the "consultative model" relies primarily on palliative care specialists; the "integrative model" builds on the internal capability of the clinical team to provide palliative care; and a third model combines features of the other two. ${ }^{83}$ Each of these models has advantages and disadvantages, as reviewed previously. ${ }^{83}$ At the present time, palliative care consultants are available in the majority of acute care hospitals, and their presence is increasing. ${ }^{84}$ Availability in longterm facilities is more limited, but expanding. ${ }^{85}$ Given the special challenges of managing symptoms, communicating about goals of care, supporting families, and planning transitions in the context of CCI, the expertise of specialists in palliative care may be especially valuable. Many palliative care teams have mechanisms in place to facilitate bereavement and other support for families. At the same time, clinicians and other healthcare providers for chronically critically ill patients and their families require basic palliative care knowledge and skills. Choice of the optimal model should be determined by local needs and resources at the individual institution. ${ }^{83}$

\section{Ethical Issues}

Important ethical issues arise in the care of the chronically critically ill. ${ }^{86}$ The most difficult dilemma is a societal one: how to provide optimal care for these patients in light of the poor prognosis for so many and the high costs in both human and economic terms. As the number of patients with CCI increases and the costs of their care continue to rise, this question will loom larger. Further research and public education are needed to address it. The role of the family or other surrogates in medical decisionmaking can create an ethical challenge if they weigh their own needs and concerns against the values and best interests of the patients for whom they have decisional responsibility. The ethical mandate of the surrogate, as currently defined, is to follow the patient's wishes previously expressed when the patient was competent, and, when these are not clear (as is most often the case), to apply "substituted judgment" of the patient or decide in the patient's best interest. ${ }^{87}$ However, the actual or perceived impact of $\mathrm{CCI}$ on the lives and well-being of families can bias the surrogate's perspective and impede patient-focused decision-making. ${ }^{44}$ Clinicians should monitor interactions with surrogates for evidence of conflicting interests and maintain the primacy of the patient's interest, engaging assistance of ethics and/or palliative care experts as needed. Another ethical issue is presented when clinicians face requests for interventions that to them seem futile- that is, not reasonably expected to accomplish an appropriate medical goal. Ideally, this issue is avoided through effective communication between the clinician and the patient or family to establish a mutually acceptable plan of care. ${ }^{88}$ Proactive ethics consultation has been studied as a means to improve communication and resolve such conflicts in the ICU setting, ${ }^{89}$ but has not been systematically evaluated in the chronically critically ill patient population. In many institutions, palliative care consultants are also available to assist in these discussions. Whether or not consensus can be achieved, the clinician is ultimately obligated to weigh the potential benefits and risks of each intervention in the exercise of professional judgment. Except as required by law, clinicians need not defer to patient or family demands for treatment imposing excessive burden in relation to expected benefit, but should explain their reasoning with clarity and sensitivity.

\section{Summary}

The majority of chronically critically ill patients are dead within 6 months: a mortality rate exceeding that for most malignancies. For most survivors, severe functional dependence persists, and impairments of cognitive function are common and profound. Few return to the community, and, in the year following the acute hospitalization, $75 \%$ of days for survivors of CCI are spent in institutional care or receiving paid home care, with multiple transitions across care settings. The impact on families is often devastating. It is difficult to imagine a group of patients with greater need for high-quality palliative care. Increasing evidence indicates that integration of pal- 


\section{Integration of Palliative Care in Chronic Critical Illness Management}

liative care with disease-directed care during serious illness, including acute and chronic critical illness, is beneficial for patients, families, clinicians, and the healthcare system. Further research to inform this care in the specific context of CCI deserves high priority from investigators and funders.

\section{REFERENCES}

1. Truog RD, Campbell ML, Curtis JR, Haas CE, Luce JM, Rubenfeld GD, et al. Recommendations for end-of-life care in the intensive care unit: a consensus statement by the American College [corrected] of Critical Care Medicine. Crit Care Med 2008;36(3):953-963. Erratum in: Crit Care Med 2008;36(5):1699.

2. Lanken PN, Terry PB, Delisser HM, Fahy BF, Hansen-Flaschen J, Heffner JE, et al. An official American Thoracic Society clinical policy statement: palliative care for patients with respiratory diseases and critical illnesses. Am J Respir Crit Care Med 2008;177(8): 912-927.

3. Selecky PA, Eliasson CA, Hall RI, Schneider RF, Varkey B, McCaffree DR. Palliative and end-of-life care for patients with cardiopulmonary diseases: American College of Chest Physicians position statement. Chest 2005;128(5):3599-3610.

4. Temel JS, Greer JA, Muzikansky A, Gallagher ER, Admane S, Jackson VA, et al. Early palliative care for patients with metastatic nonsmall-cell lung cancer. N Engl J Med 2010;363(8):733-742.

5. Bakitas M, Lyons KD, Hegel MT, Balan S, Brokaw FC, Seville J, et al. Effects of a palliative care intervention on clinical outcomes in patients with advanced cancer: the Project ENABLE II randomized controlled trial. JAMA 2009;302(7):741-749.

6. Morrison RS, Penrod JD, Cassel JB, Caust-Ellenbogen M, Litke A, Spragens L, et al. Cost savings associated with US hospital palliative care consultation programs. Arch Intern Med 2008;168(16): 1783-1790.

7. Casarett D, Pickard A, Bailey FA, Ritchie C, Furman C, Rosenfeld $\mathrm{K}$, et al. Do palliative consultations improve patient outcomes? J Am Geriatr Soc 2008;56(4):593-599.

8. Nelson JE, Cox CE, Hope AA, Carson SS. Concise clinical review: chronic critical illness. Am J Respir Crit Care Med 2010;182(4): 446-454.

9. Nelson JE, Meier DE, Litke A, Natale DA, Siegel RE, Morrison RS. The symptom burden of chronic critical illness. Crit Care Med 2004; 32(7):1527-1534

10. Jubran A, Lawm G, Kelly J, Duffner LA, Gungor G, Collins EG, et al. Depressive disorders during weaning from prolonged mechanical ventilation. Intensive Care Med 2010;36(5):828-835.

11. American Psychiatric Association. Diagnostic and statistical manual of mental disorder. Washington DC: APA; 2000.

12. Payen JF, Bosson JL, Chanques G, Mantz J, Labarere J. Pain assessment is associated with decreased duration of mechanical ventilation in the intensive care unit: a post hoc analysis of the DOLOREA study. Anesthesiology 2009;111(6):1308-1316.

13. Chang VT, Thaler HT, Polyak HT, Kornblith AB, Lepore JM, Portenoy RK. Quality of life and survival. Cancer 1998;83(1):173-179.

14. Covinsky KE, Kahana E, Chin MH, Palmer RM, Fortinsky RH, Landefeld CS. Depressive symptoms and 3-year mortality in older hospitalized medical patients. Ann Intern Med 1999;130(7): 563-569.

15. Nelson JE, Tandon N, Mercado AF, Camhi SL, Ely EW, Morrison RS. Brain dysfunction: another burden for the chronically critically ill. Arch Intern Med 2006;166(18):1993-1999.

16. Chang VT, Hwang SS, Kasimis B, Thaler HT. Shorter symptom assessment instruments: the Condensed Memorial Symptom Assessment Scale (CMSAS). Cancer Invest 2004;22(4):526-536.
17. Bruera E, Kuehn N, Miller MJ, Selmser P, Macmillan K. The Edmonton Symptom Assessment System (ESAS): a simple method for the assessment of palliative care patients. J Pall Care 1991;7(2):6-9.

18. Melzack R. The short-form McGill Pain Questionnaire. Pain 1987; 30(2):191-197.

19. Chochinov HM, Wilson KG, Enns M, Lander S. "Are you depressed?" Screening for depression in the terminally ill Am J Psych 1997; 154(5):674-676.

20. Dorman S, Byrne A, Edwards A. Which measurement scales should we use to measure breathlessness in palliative care? A systematic review. Palliat Med 2007;21(3):177-191.

21. Payen JF, Bru O, Bosson JL, Lagrasta A, Novel E, Deschaux I, et al. Assessing pain in critically ill sedated patients by using a behavioral pain scale. Crit Care Med 2001;29(12):2258-2263.

22. Gelinas C, Fortier M, Viens C, Fillion L, Puntillo K. Pain assessment and management in critically ill intubated patients: a retrospective study. Am J Crit Care 2004;13(2):126-135.

23. Herr K, Coyne PJ, Key T, Manworren R, McCaffery M, Merkel S, et al. Pain assessment in the nonverbal patient: position statement with clinical practice recommendations. Pain Manag Nurs 2006; $7(2): 44-52$.

24. Campbell ML, Templin T, Walch J. A Respiratory Distress Observation Scale for patients unable to self-report dyspnea. J Palliat Med 2010;13(3):285-290

25. Lee D, Higgins PA. Adjunctive therapies for the chronically critically ill. AACN Adv Crit Care 2010;21(1):92-106.

26. Pan CX, Morrison RS, Ness J, Fugh-Berman A, Leipzig RM. Complementary and alternative medicine in the management of pain, dyspnea, and nausea and vomiting near the end of life. A systematic review. J Pain Symptom Manage 2000;20(5):374-387.

27. Tiseo P, Thaler HT, Lapin J, Inturrisi CE, Portenoy RK, Foley KM. Morphine-6-glururonide concentrations and opioid related side effects-a survey in cancer patients. Pain 1995;61(1):47-54.

28. Smith MT, Watt JA, Cramond T. Morphine-3-glucuronide: a potent antagonist of morphine analgesia. Life Sci 1990;47(6):579-585.

29. Center to Advance Palliative Care. http://www.capc.org/tools-forpalliative-care-programs/clinical-tools/pocket-clinical- cards/mssmpain-card.pdf. Accessed March 30, 2012.

30. Mahler DA, Selecky PA, Harrod CG, Benditt JO, Carrieri-Kohlman V, Curtis JR, et al. American College of Chest Physicians consensus statement on the management of dyspnea in patients with advanced lung or heart disease. Chest. 2010 Mar;137(3):674-691.

31. Nelson JE. Palliative care of the chronically critically ill patient. Crit Care Clin 2002;18(3):659-682.

32. Dews TE, Mekhail N. Safe use of opioids in chronic noncancer pain. Cleve Clin J Med 2004;71(11):897-904.

33. Radtke JV, Baumann BM, Garrett KL, Happ MB. Listening to the voiceless patient: case reports in assisted communication in the intensive care unit. J Palliat Med 2011;14(6):791-795.

34. Desai A, Rho L, Nelson J. Helping the chronically critically ill to communicate: speaking valve pilot trial (abstract). Am J Respir Crit Care Med 2009;179(1):A3083.

35. Rothenhausler HB, Ehrentraut S, von Degenfeld G, Weis M, Tichy M, Kilger E, et al. Treatment of depression with methylphenidate in patients difficult to wean from mechanical ventilation in the intensive care unit. J Clin Psychiatry 2000;61(10):750-755.

36. Johnson CJ, Auger WR, Fedullo PF. Methylphenidate in the hard to wean patient. J Psychosom Res 1995;39(1):63-68.

37. Nelson JE, Kinjo K, Meier DE, Ahmad K, Morrison RS. When critical illness becomes chronic: informational needs of patients and families. J Crit Care 2005;20(1):79-89.

38. Unroe M, Kahn JM, Carson SS, Govert JA, Martinu T, Sathy SJ, et al. One-year trajectories of care and resource utilization for recip- 


\section{Integration of Palliative Care in Chronic Critical Illness Management}

ients of prolonged mechanical ventilation: a cohort study. Ann Intern Med 2010;153(3):167-175.

39. Cox CE, Martinu T, Sathy SJ, Clay AS, Chia J, Gray AL, et al. Expectations and outcomes of prolonged mechanical ventilation. Crit Care Med 2009;37(11):2888-2894

40. Davidson JE, Powers K, Hedayat KM, Tieszen M, Kon AA, Shepard E, et al. Clinical practice guidelines for support of the family in the patient-centered intensive care unit: American College of Critical Care Medicine Task Force 2004-2005. Crit Care Med 2007;35(2): 605-622.

41. Kon AA. The shared decision-making continuum. JAMA 2010; 304(8):903-904

42. Camhi SL, Mercado AF, Morrison RS, Du Q, Platt DM, August GI, et al. Deciding in the dark: advance directives and continuation of treatment in chronic critical illness. Crit Care Med 2009;37(3): 919-925.

43. Sulmasy DP, Terry PB, Weisman CS, Miller DJ, Stallings RY, Vettese MA, et al. The accuracy of substituted judgments in patients with terminal diagnoses. Ann Intern Med 1998;128(8):621-629.

44. Pochard F, Azoulay E, Chevret S, Lemaire F, Hubert P, Canoui P, et al. Symptoms of anxiety and depression in family members of intensive care unit patients: ethical hypothesis regarding decisionmaking capacity. Crit Care Med 2001;29(10):1893-1897.

45. Nelson JE, Cortez TB, Curtis JR, Lustbader D, Mosenthal AC, Mulkerin C, et al. Integrating palliative care in the ICU: the nurse in a leading role. J Hosp Palliat Nurs 2011;13(2):89-94.

46. Krimshtein NS, Luhrs CA, Puntillo K, Cortez TB, Livote EE, Penrod J, et al. Training nurses for interdisciplinary communication with families in the intensive care unit: an intervention. J Palliat Med 2011;14(12):1325-1332.

47. McDonagh JR, Elliott TB, Engelberg RA, Treece PD, Shannon SE, Rubenfeld GD, et al. Family satisfaction with family conferences about end-of-life care in the intensive care unit: increased proportion of family speech is associated with increased satisfaction. Crit Care Med 2004;32(7):1484-1487.

48. Back AL, Arnold RM, Baile WF, Tulsky JA, Fryer-Edwards K. Approaching difficult communication tasks in oncology. CA Cancer J Clin 2005;55(3):164-177.

49. Curtis JR, Engelberg RA, Wenrich MD, Shannon SE, Treece PD, Rubenfeld GD. Missed opportunities during family conferences about end-of-life care in the intensive care unit. Am J Respir Crit Care Med 2005;171(8):844-849.

50. Selph RB, Shiang J, Engelberg R, Curtis JR, White DB. Empathy and life support decisions in intensive care units. J Gen Intern Med 2008;23(9):1311-1317.

51. Back A, Arnold R, Tulsky J. Mastering communication with seriously ill patients: balancing honesty with empathy and hope. New York: Cambridge University Press; 2009.

52. Fogarty LA, Curbow BA, Wingard JR, McDonnell K, Somerfield MR. Can 40 seconds of compassion reduce patient anxiety? J Clin Oncol 1999;17(1):371-379.

53. Pollak KI, Arnold RM, Jeffreys AS, Alexander SC, Olsen MK, Abernethy AP, et al. Oncologist communication about emotion during visits with patients with advanced cancer. J Clin Oncol 2007; 25(36):5748-5752.

54. Stapleton RD, Engelberg RA, Wenrich MD, Goss CH, Curtis JR. Clinician statements and family satisfaction with family conferences in the intensive care unit. Crit Care Med 2006;34(6):1679-1685.

55. Widera EW, Rosenfeld KE, Fromme EK, Sulmasy DP, Arnold RM. Approaching patients and family members who hope for a miracle. J Pain Symptom Manage 2011;42(1):119-125.

56. Quill T, Arnold R, Back AL. Discussing treatment preferences with patients who want "everything". Ann Intern Med 2009;151(5): 345-349.
57. Nelson JE, Mercado AF, Camhi SL, Tandon N, Wallenstein S, August GI, et al. Communication about chronic critical illness. Arch Intern Med 2007;167(22):2509-2515.

58. Boyd EA, Lo B, Evans LR, Malvar G, Apatira L, Luce JM, et al. "It's not just what the doctor tells me:" factors that influence surrogate decision-makers' perceptions of prognosis. Crit Care Med 2010; 38(5):1270-1275.

59. Lee Char SJ, Evans LR, Malvar GL, White DB. A randomized trial of two methods to disclose prognosis to surrogate decision makers in intensive care units. Am J Respir Crit Care Med 2010;182(7): 905-909.

60. Carson SS, Garrett J, Hanson LC, Lanier J, Govert J, Brake MC, et al. A prognostic model for one-year mortality in patients requiring prolonged mechanical ventilation. Crit Care Med 2008;36(7): 2061-2069.

61. Society of Critical Care Medicine. Chronic critical illness in adults requiring prolonged mechanical ventilation. http://www.myicucare. org/Support_Brochures/Pages/ChronicCriticalIllness.aspx. Accessed March 30, 2012.

62. Lautrette A, Darmon M, Megarbane B, Joly LM, Chevret S, Adrie C, et al. A communication strategy and brochure for relatives of patients dying in the ICU. N Engl J Med 2007;356(5):469-478.

63. Azoulay E, Pochard F, Chevret S, Jourdain M, Bornstain C, Wernet A, et al. Impact of a family information leaflet on effectiveness of information provided to family members of intensive care unit patients: a multicenter, prospective, randomized, controlled trial. Am J Respir Crit Care Med 2002;165(4):438-442.

64. Nelson JE, Walker AS, Luhrs CA, Cortez TB, Pronovost PJ. Family meetings made simpler: a toolkit for the intensive care unit. J Crit Care 2009;24(4):626.e7-e14.

65. IPAC-ICU Project. Meeting with the ICU team: a guide for families. http://www.capc.org/ipal-icu/patient-family-resources/meetingwith-the-icu-team-a-guide-for-families.pdf. Accessed September 3 , 2011

66. Center to Advance Palliative Care. http://www.capc.org/signup? tool=/clinical-tools/patient-assessment. Accessed March 30, 2012.

67. Department of Health and Human Services; Centers for Medicare and Medicaid. Medicare claims processing. Pub. 100-04. Washington DC: CMS; July 2008. http://www.cms.gov/Transmittals/ downloads/R1548CP.pdf. Accessed March 30, 2012.

68. Swoboda SM, Lipsett PA. Impact of a prolonged surgical critical illness on patients' families. Am J Crit Care 2002;11(5):459-466.

69. Van Pelt DC, Milbrandt EB, Qin L, Weissfeld LA, Rotondi AJ, Schulz R, et al. Informal caregiver burden among survivors of prolonged mechanical ventilation. Am J Respir Crit Care Med 2007; 175(2):167-173.

70. Choi J, Donahoe MP, Zullo TG, Hoffman LA. Caregivers of the chronically critically ill after discharge from the intensive care unit: six months' experience. Am J Crit Care 2011;20(1):12-22.

71. Schulz R, Beach SR. Caregiving as a risk factor for mortality: the Caregiver Health Effects Study. JAMA 1999;282(23):2215-2219.

72. Douglas SL, Daly BJ. Caregivers of long-term ventilator patients: physical and psychological outcomes. Chest 2003;123(4):1073-1081.

73. Douglas SL, Daly BJ, O'Toole E, Hickman RL Jr. Depression among white and nonwhite caregivers of the chronically critically ill. J Crit Care 2010;25(2):364, e311-e369.

74. Im K, Belle SH, Schulz R, Mendelsohn AB, Chelluri L. Prevalence and outcomes of caregiving after prolonged ( $>$ or $=48$ hours) mechanical ventilation in the ICU. Chest 2004;125(2):597-606.

75. Azoulay E, Pochard F, Kentish-Barnes N, Chevret S, Aboab J, Adrie $\mathrm{C}$, et al. Risk of post-traumatic stress symptoms in family members of intensive care unit patients. Am J Respir Crit Care Med 2005; 171(9):987-994. 
76. Jones C, Skirrow P, Griffiths RD, Humphris G, Ingleby S, Eddleston $\mathrm{J}$, et al. Post-traumatic stress disorder-related symptoms in relatives of patients following intensive care. Intensive Care Med 2004;30(3): 456-460.

77. Anderson WG, Arnold RM, Angus DC, Bryce CL. Posttraumatic stress and complicated grief in family members of patients in the intensive care unit. J Gen Intern Med 2008;23(11):18711876.

78. Paparrigopoulos T, Melissaki A, Efthymiou A, Tsekou H, Vadala C, Kribeni G, et al. Short-term psychological impact on family members of intensive care unit patients. J Psychosom Res 2006;61(5): 719-722.

79. Hickman RL, Jr., Douglas SL. Impact of chronic critical illness on the psychological outcomes of family members. AACN Adv Crit Care 2010;21(1):80-91.

80. Siegel MD, Hayes E, Vanderwerker LC, Loseth DB, Prigerson HG. Psychiatric illness in the next of kin of patients who die in the intensive care unit. Crit Care Med 2008;36(6):1722-1728.

81. Douglas SL, Daly BJ, Kelley CG, O’Toole E, Montenegro H. Impact of a disease management program upon caregivers of chronically critically ill patients. Chest 2005;128(6):3925-3936.

82. Daly BJ, Douglas SL, Kelley CG, O’Toole E, Montenegro H. Trial of a disease management program to reduce hospital readmissions of the chronically critically ill. Chest 2005;128(2):507-517.

83. Nelson JE, Bassett R, Boss RD, Brasel K, Campbell ML, Cortez TB, et al. Models for structuring a clinical initiative to enhance palliative care in the intensive care unit: a report from the Improve Palliative Care in the ICU (IPAL-ICU) Project and the Center to Advance Palliative Care. Crit Care Med 2010;38(9):1765-1772.

84. Center to Advance Palliative Care. Growth of palliative care in US hospitals: 2011 snapsnot. http://www.capc.org/news-and-events/ releases/capc-growth-snapshot-2011.pdf. Accessed March 30, 2012.

85. Keay TJ, Schonwetter RS. The case for hospice care in long-term care environments. Clin Geriatr Med 2000;16(2):211-223.

86. Papa-Kanaan JM, Sicilian L. Ethical issues in the chronically critically ill patient. Clin Chest Med 2001;22(1):209-217.

87. Beauchamp TL, Childress JF. Principles of biomedical ethics. New York: Oxford University Press; 2009:135-140.

88. Burns JP, Truog RD. Futility: a concept in evolution. Chest 2007; 132(6):1987-1993.

89. Schneiderman LJ, Gilmer T, Teetzel HD, Dugan DO, Blustein J, Cranford R, et al. Effect of ethics consultations on nonbeneficial life-sustaining treatments in the intensive care setting: a randomized controlled trial. JAMA 2003;290(9):1166-1172.

\section{Discussion}

MacIntyre: You focused, and I understand why, on the physician-patient relationship. In my experience, it's important to have the entire team on board here. You have nurses who are with the patient 24 hours a day, and RTs [respiratory therapists] and physical therapists at the bedside a lot. I think it's critical that all of them are saying the same thing, or you can have a wonderful physicianpatient-surrogate discussion, only to have the nurse say something completely different.

Nelson: I'm really glad you brought that up, Neil, because the entire interdisciplinary team is crucial. The nurses in particular have a huge role in this communication process. One factor is that the nurse is at the bedside more than anybody else, and, in a fragmented system, hears disparate communications between patients and families and various clinicians. Usually the nurse has an excellent relationship with the family and an understanding of both the medical information and the patient and family.
We have been training nurses in communication skills, with the belief that, as part of an interdisciplinary team, nurses can be active and very effective participants in discussions with patients and their surrogates. We've been doing that in the Veterans Affairs system and the Voluntary Hospital Association. There are also chaplains, RTs, and others.

MacIntyre: Since this is respiratory focus, in my institution the families like to ask the RTs, because they are presumed to be the ventilator expertswhere this ventilator management is going and what it's doing. It's important that they're saying the same thing, too.

Nelson: Correct. Ideally the communication is integrated, because otherwise patients or families may take a fragment out of context.

Snyder: " With that respiratory focus, I'd like to highlight something

\footnotetext{
* Lisa Snyder MD MPH, Select Medical, Mechanicsburg, Pennsylvania.
}

you said, and I'm very glad you said it. In several of our hospitals we use speaking valves, and for the staff, the physicians, the RTs, and especially the families who get that chance to hear their loved one communicate, it is very heartwarming and there are tears. It's very uplifting, not only for the family, but for the staff as well, so I'm really glad you highlighted that. It's really a game-changer in people's treatment plans.

Nelson: I agree, and I think the RTs are essential in making that happen in a safe and effective way. We were also very impressed by the impact of this.

Mechanick: I want to repeat a question you mentioned to me after my presentation, which was, despite all the rhetoric and technological advances, why have we not made more progress? You would think that with all of this sophisticated intervention, every patient should be liberated from the ventilator. The point is that, 
in theory, this process is very complicated and there are many other factors and most likely a threshold phenomenon. With that in mind, I want to offer to you that, just because you have something a little "softer," such as symptom burdens and palliative care, than "hard science" - and I'm using those terms in quotes, as extremes, it isn't pejorativethat does not mean that the two paradigms cannot be coordinated. It turns out that scientifically defined events like allostatic load are still affected by less-defined events, like having a pet or family or music at the bedside, or changing the light/dark cycle. These events are all scientifically and evidencebased to some degree, and certainly approaching symptom burden and palliation are going to act within gray areas to restore a normal, low-stress allostatic state and have as good an impact on recovery as anything as sophisticated as discrete metabolic interventions or antibiotics.

Nelson: I think the days are long gone when we could look at palliative care as a soft, fuzzy area. It's a medical specialty, it's an area of scientific research, and it's a highly effective form of treatment when integrated with others. 